\title{
Reproduction obstacles for the female green neon shrimp (Neocaridina denticulata) after exposure to chlordane and lindane
}

\author{
Da-Ji Huang a , Hon-Cheng Chen ${ }^{\mathrm{b}}$, Jui-Pin Wu ${ }^{\mathrm{c}}$, Shu-Yin Wang ${ }^{\mathrm{d}, *}$ \\ ${ }^{a}$ Department of Environmental Resources Management, Chia Nan University of Pharmacy and Science, Tainan 71710, Taiwan, ROC \\ ${ }^{\mathrm{b}}$ Institute of Fisheries Sciences, National Taiwan University, Taipei 106, Taiwan, ROC \\ ${ }^{\mathrm{c}}$ Institute of Zoology, National Taiwan University, Taipei 106, Taiwan, ROC \\ d Department of Animal Science, Chinese Culture University, Yang Ming Shan, Taipei 111, Taiwan, ROC
}

Received 3 August 2005; received in revised form 29 November 2005; accepted 10 December 2005

Available online 29 March 2006

\begin{abstract}
The purpose of this study was to investigate the effects of chlordane and lindane on reproduction obstacles and endocrine disruption in female green neon shrimp (Neocaridina denticulata). Individuals of $N$. denticulata, a common inhabitant of freshwater systems in Taiwan, was exposed to different levels of chlordane $\left(1\right.$ and $\left.10 \mathrm{ng} \mathrm{l}^{-1}\right)$ and lindane $\left(0.1\right.$ and $\left.1 \mu \mathrm{g} \mathrm{l}^{-1}\right)$. The reproductive ability and reproductive hormone levels were observed after exposure. According to our findings, an increase in estrogen, induction of a vitellogenin-like protein, and changes in reproductive performance were observed in both chlordane- and lindane-treated shrimp. Thus, it was concluded that chlordane and lindane may cause some reproduction obstacles and disruption of endocrine functions in $N$. denticulata.

(C) 2005 Elsevier Ltd. All rights reserved.
\end{abstract}

Keywords: Reproduction obstacle; Endocrine-disrupting chemicals; Chlordane; Lindane; Neocaridina denticulata

\section{Introduction}

Chlordane and lindane, both organochlorine pesticides (OCPs), are widely distributed contaminants in environments such as aquatic systems and act as endocrine-disrupting chemicals (EDCs) in many organisms. OCPs are some of the most-dangerous pesticides because of their toxicity, stability, high liposolubility, and long biological halflives. OCPs can exhibit a high degree of bioaccumulation and biomagnification within food chains (Colborn et al., 1993; Colborn and Thayer, 2000), and are known to have

\footnotetext{
* Corresponding author. Tel.: +886 $228610511 \times 543$; fax: +886 2 28613100.

E-mail addresses: daji@ms19.hinet.net (D.-J. Huang), honcheng@ ccms.ntu.edu.tw (H.-C. Chen), rb5_wu@yahoo.com.tw (J.-P. Wu), sywang@faculty.pccu.edu.tw (S.-Y. Wang).
}

carcinogenic, teratogenic, and endocrine-disruptive effects in humans and wildlife (Crain and Guillette, 1998). Previous studies showed that chlordane may have complex and variable biological functions such as estrogen-like functions, while lindane has estrogenic-like effects on some organisms, but antiestrogenic effects on others (Huang and Chen, 2004; Huang et al., 2004). Chlordane and lindane have been shown to exhibit effects similar to those of EDCs. In animal studies, these compounds were shown to exhibit an estrogenic-like effect, and to have detrimental effects on reproductive systems (Colborn et al., 1993). Although many developing and developed countries have prohibited the use of these compounds for many years, OCPs are consistently detected in ecosystems (Chen et al., 1999). Therefore, the influence of OCP residues on the development of wildlife has become a major concern.

There were several reports of hormone changes, reproductive incompetence, and altered reproductive behavior 
after exposure to xenoestrogen (Colborn et al., 1993; Sharara et al., 1998). Crustaceans are frequently used as target animals in aquatic systems to examine the presence of EDCs (Depledge and Billinghurst, 1999; Hutchinson, 2002). The physiological roles of the "vertebrate type" steroid hormones, testosterone and estrogen, have been identified in shrimp (Quinitio et al., 1991; Cardoso et al., 1997). Treatment with natural vertebrate estrogen was reported to induce maturation in crustaceans (Rinderhagen et al., 2000). Several reports showed that the natural hormone and xenoestrogen can effect sexual development and sexual hormone regulation (Colborn et al., 1993; Sharara et al., 1998). Our previous studies demonstrated that chlordane and lindane caused changes in testosterone and vitellogenin $(\mathrm{Vg})$ levels in juvenile and male shrimp ( $N$. denticulata) (Huang and Chen, 2004; Huang et al., 2004).

Atyid shrimp are common inhabitants of freshwater systems. In Taiwan, 13 species of atyid shrimp belonging to three genera have been described, among which, Neocaridina denticulata is the only one belonging to the genus Neocaridina (Hung et al., 1993). This species is commonly and extensively distributed in many streams, ponds, swamps, and rivers in East Asia and the Hawaiian islands (Hung et al., 1993; Englund and Cai, 1999). Because of this, $N$. denticulata is one of the most-commonly used aquatic organisms for environmentally related studies of freshwater systems (Chen et al., 1999). However, the quantity of $N$. denticulata in natural habitats in Taiwan is on the decline due to human activities, including pollution, destruction of natural habitats, and overfishing (Shy and $\mathrm{Yu}, 1998)$.

Despite having a widespread distribution, only a few attempts have been made to determine the impacts of chlordane and lindane in fresh water on $N$. denticulata. The purpose of this study was to investigate the effect of chlordane and lindane exposure to the reproductive activity, vitellogenesis and estradiol secretion in female $N$. denticulate.

\section{Materials and methods}

\subsection{Shrimp collection and maintenance}

Green neon shrimp ( $N$. denticulata) were taken from rivers in Taipei County, northern Taiwan and were transferred to a 50-1 glass aquarium The aquarium was equipped with a water-cycling device, $\mathrm{pH}$ was maintained at 7.4-7.8, dissolved oxygen concentration was maintained above $7.3 \mathrm{mg}^{-1}$, and the hardness of water was in the range of $38-45 \mathrm{mg} \mathrm{CaCO}_{3} 1^{-1}$. Temperature was maintained at $25 \pm 1{ }^{\circ} \mathrm{C}$, and a 12-h light-dark photoperiod was used. Under these conditions, shrimp were fed twice a day and were allowed to acclimate for 2 weeks before testing. Compositions of the commercial shrimp feed are as following: crude protein $\geqq 38-40 \%$, crude fat $\geqq 3-4 \%$, crude Ash $\leqq 15-16 \%$, crude fiber $\leqq 2.5-3 \%$, and moisture $\leqq 10-11 \%$.

\subsection{Exposure of shrimp to $17 \beta$-estradiol, chlordane, and lindane}

The 96-h $\mathrm{LC}_{50}$ levels for chlordane and lindane for $N$. denticulata were $127.03 \mathrm{ng}^{-1}$ and $9.36 \mu \mathrm{g}^{-1}$, respectively based on the study by Huang and Chen (2004). Sublethal concentrations of chlordane and lindane used in the experiments were 1 and $10 \mathrm{ng}^{-1}$ and 0.1 and $1 \mu \mathrm{g}^{-1}$, respectively. Positive controls (10 and $100 \mu \mathrm{g}^{-1} 17 \beta$-estradiol in alcohol) with no pesticide added were also carried out, as well as a vehicle control group in which only acetone was added as vehicle and quantity added was about 100 $\mu \mathrm{g} 1^{-1}$. In total, 50 female shrimp (body length, 13$16 \mathrm{~mm}$ ) with similar body size were used for each group (in a 10-1 glass beaker, run in triplicate for each determination). Water renewal in toxicity tests was in $48 \mathrm{~h}$ interval (EPA/ROC, 1998). Sex differentiation was determined based on the observation of appendix masculine, as the shape becomes oval and surrounded by cilia (Hung et al., 1993; Shy and Yu, 1998; Englund and Cai, 1999; Huang and Chen, 2004).

\subsection{Test of reproductive ability}

Lindane and chlordane were tested separately. For each treatment, 20 each of male and female shrimps were put into a 101 beaker and were allowed to mate. The lag time prior to oogenesis was recorded. At the time of oogenesis, the body length of female shrimp, number (sprawling amount) and size (diameter) of eggs were determined. Female shrimps were then transferred to a 11 beaker and still treated with lindane or chlordane for brooding until the eggs were hatched. The brooding time and the number hatched were recorded and the hatching rate was calculated.

\subsection{Sample preparation}

For determination of estradiol and vitellogenin, samples were taken at the end of days $1,3,7,14$, and 28. Three shrimp were pooled and homogenized with a Teflon pestle (Kontes, Vineland, NJ, USA) in ice-cold $25 \mathrm{mM}$ Tris- $\mathrm{HCl}$ with EDTA. The homogenate was centrifuged at $10000 \mathrm{~g}$ (for $20 \mathrm{~min}$ at $4{ }^{\circ} \mathrm{C}$ ), and the supernatant was collected and stored at $-20^{\circ} \mathrm{C}$ until analysis.

\subsection{Determination of hemolymph estradiol}

Levels of estradiol were determined using an EIA kit (DSLabs, Webster, TX, USA). The assay uses a competitive binding enzyme immunoassay format (Maxey et al., 1992). In the assay, standards, controls, and unknowns containing estradiol were incubated with biotin-labeled estradiol and rabbit anti-estradiol antiserum in microtitration wells where the unlabeled and biotin-labeled antigens compete for limited binding sites for the first antibody. After incubation and washing, streptavidin-HRPO was 
added into the wells for binding with biotinylated estradiol. The unbound streptavidin-HRPO was washed, followed by incubation with the substrate, tetramethylbenzidine (TMB). An acidic stopping solution was then added, and the degree of enzymatic turnover of the substrate was determined by dual-wavelength absorbance measurements at 450 and $620 \mathrm{~nm}$.

\subsection{Determination of hemolymph vitellogenin}

The level of vitellogenin-like protein in the hemolymph was immediately determined using an alkali-labile phosphate (ALP) assay adapted from the description by Gangé and Blaise (2000). Shrimp hemolymph (in 5 and $45 \mu$ of $25 \mathrm{mM}$ Tris- $\mathrm{HCl}$ buffer, $\mathrm{pH} 7.5$ ) was mixed with $50 \mu 1$ of ice-cold 20\% trichloroacetic acid (TCA) and incubated at room temperature for $15 \mathrm{~min}$. The mixture was centrifuged at $10000 \mathrm{~g}$ for $10 \mathrm{~min}$ at $4{ }^{\circ} \mathrm{C}$. The protein pellet was resuspended in $200 \mu \mathrm{l}$ of $1 \mathrm{M} \mathrm{NaOH}$ and heated to $75^{\circ} \mathrm{C}$ for $60 \mathrm{~min}$ for determination of the free phosphate level by the phosphomolybdenum method, and the optical absorbance was read at $600 \mathrm{~nm}$ (Ellman et al., 1961; Gangé and Blaise, 2000).

\subsection{Statistical analysis}

Statistical analysis was carried out using Microcal $^{\mathrm{TM}}$ origin 6.0. (Northampton, MA, USA, 1999). Means of each treatment group were compared using Student's $t$-test (paired assay), and $p<0.05$ was accepted as statistically significant.

\section{Results}

\subsection{Levels of estradiol in hemolymph}

High levels of estradiol were detected in female of $N$. denticulata after treated with $17 \beta$-estradiol, chlordane, and lindane $(p<0.01)$ (Fig. 1). The $R^{2}$ values of the standard curves in estradiol assays were greater than 0.99; the standard check and relative percent difference were less than $10 \%$ and $5 \%$, respectively.

\subsection{Vitellogenin levels in hemolymph}

Treatment with $17 \beta$-estradiol, chlordane, and lindane changed the levels of vitellogenin $(\mathrm{Vg})$ in the hemolymph, as determined by the ALP assay. Vg levels in female $N$. denticulata hemolymph were induced by treatment with $10 \mu \mathrm{g}^{-1} 17 \beta$-estradiol on days 3 and $7,(p<0.05)$, while $100 \mu \mathrm{g}^{-1} 17 \beta$-estradiol caused a significant increase in $\mathrm{Vg}$ levels only after 3 days of exposure $(p<0.05)$. Vg was induced in female $N$. denticulata treated with $10 \mathrm{ng}^{-1}$ chlordane for 1 and 3 days, while $1 \mathrm{ng} 1^{-1}$ chlordane caused a significant increase in $\mathrm{Vg}$ levels only after 3 days of exposure $(p<0.05)$. There were significant differences between the treatment groups $\left(0.1\right.$ and $1 \mu \mathrm{g} 1^{-1}$ lindane) and the
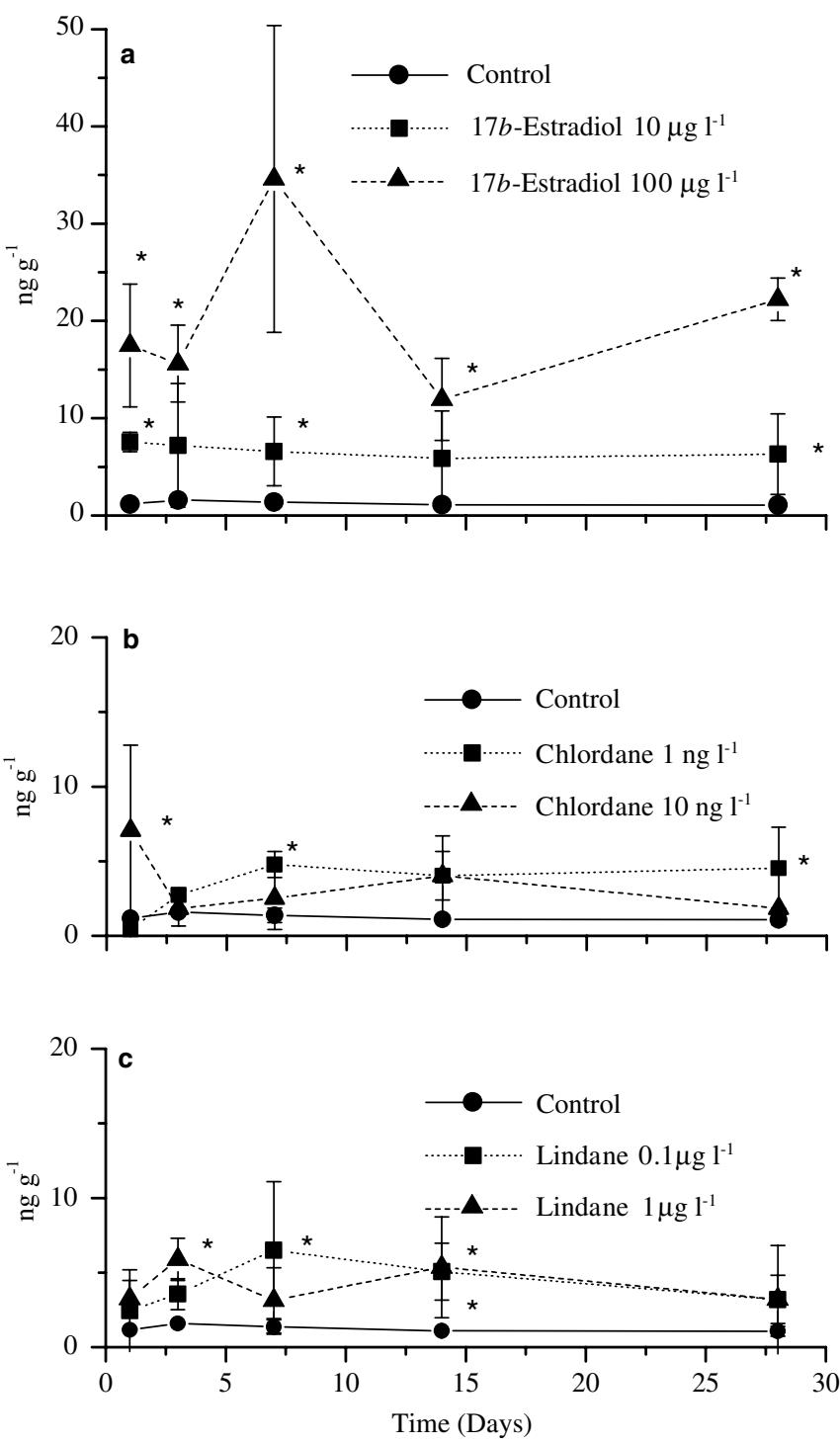

Fig. 1. Hemolymph estradiol levels in female Neocaridina denticulata exposed to $17 \beta$-estradiol, chlordane, and lindane for 28 days (mean $\pm \mathrm{SD}$, $n=15)$. An asterisk $\left({ }^{*}\right)$ indicates a difference between the treatment and control group was significant at $p<0.05$.

control group on day 1 and 7, and on days 1, respectively (Fig. 2). The $R^{2}$ value of the standard curve for the $\mathrm{Vg}$ assay was $0.9965(>0.99)$; the standard check and relative percent difference were $2.11 \%(<10 \%)$ and $4.21 \%(<5 \%)$, respectively.

\subsection{Test of reproductive ability}

The fertility and general reproductive performance experiments on female shrimp were carried out beginning from April 2004. The lag time to oogenesis for control female shrimp was $48.8 \pm 7.1$ days, the ovigerous rate was $40 \%$, and the body length was $1.84 \pm 0.17 \mathrm{~cm}$. The number of ovigerous female and the number hatched were $31.4 \pm 8.1$ and $23.0 \pm 8.1$, respectively. The normal size of the eggs was $1.04 \pm 0.01 \mathrm{~mm}$ in diameter and the hatching 

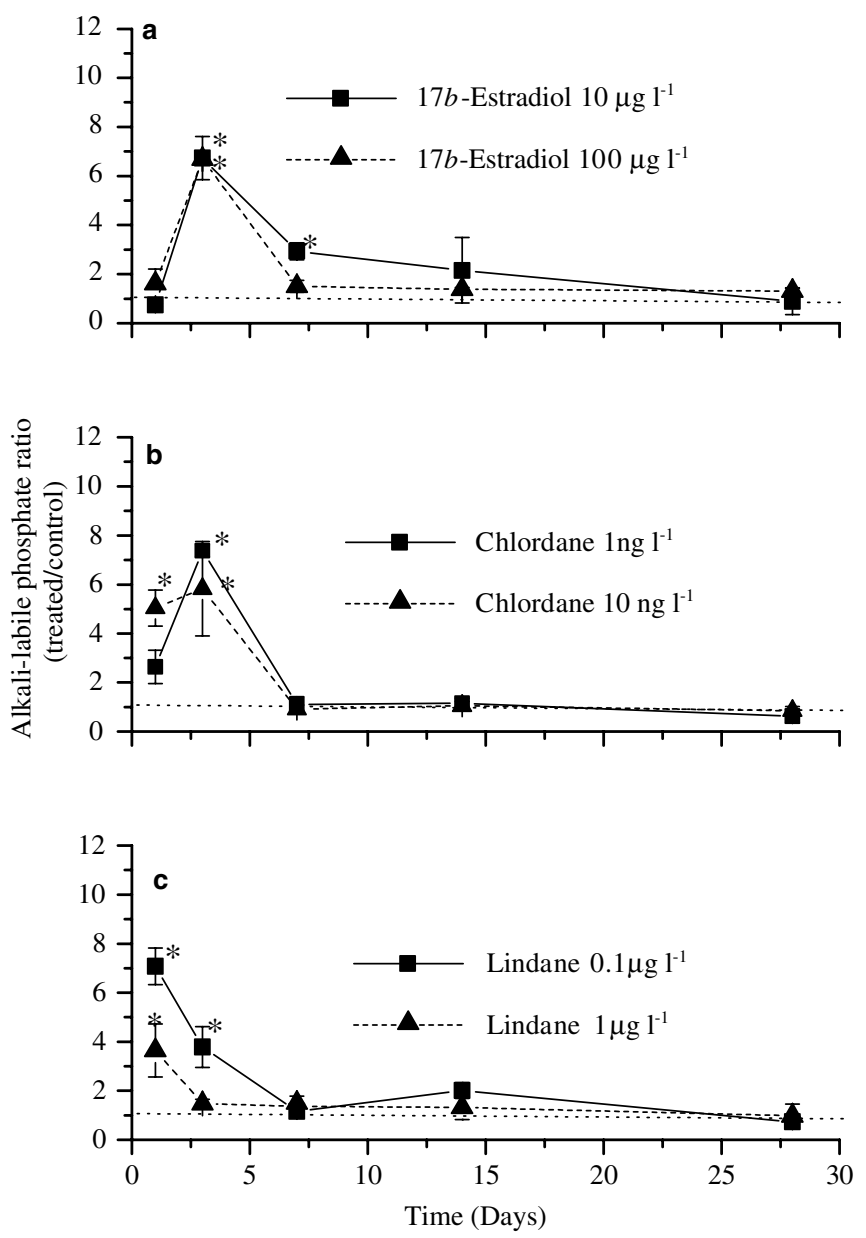

Fig. 2. Hemolymph APL response levels in female Neocaridina denticulata exposed to $17 \beta$-estradiol, chlordane, and lindane for $1,3,7,14$, and 28 days (mean $\pm \mathrm{SD}, n=15$ ). An asterisk $\left({ }^{*}\right)$ indicates that a difference between the experimental and control group was significant at $p<0.05$.

rate was $73.2 \%$ (Table 1). During the experiment, no ovigerous female shrimp were found in the $10 \mathrm{ng} 1^{-1}$ chlordane $(\mathrm{CH}-10)$ treatment group. Although two and one ovigerous female shrimp were found in the $100 \mu \mathrm{g}^{-1} 17 \beta$-estradiol
(E2-100) and $1 \mu \mathrm{g}^{-1}$ lindane (L1) treatment group, respectively, they all died 3 days after oogenesis. The ovigerous rate and lag time to oogenesis of female shrimp in the $10 \mu \mathrm{g}^{-1} 17 \beta$-estradiol (E2-10) group were $40 \%$ and $31.8 \pm$ 6.9 days, in the $1 \mathrm{ng}^{-1}$ chlordane $(\mathrm{CH}-1)$ group were $30 \%$ and $36.7 \pm 5.8$ days, and in the $0.1 \mu \mathrm{g} 1^{-1}$ lindane (L0.1) group were $10 \%$ and $25.0 \pm 1.4$ days, respectively. In this experiment, ovigerous times of the E2-10 and L0.1 groups were shorter than that of the control group, while egg diameters in the two experimental groups were larger than that of the control group $(p<0.05)$. The ovigerous number of the E2-10 group ( $52.8 \pm 6.0)$ was higher than that of the control group; but that of the $\mathrm{CH}-1$ group $(14.0 \pm 1.4)$ was lower than that of the control group $(p<0.05)$. In the L0.1 group, no larval shrimp hatched. The hatching rates of female shrimp of the E2-10 (25.6\%) and $\mathrm{CH}-1(4.8 \%)$ groups were lower than control group $(p<0.05)$.

\section{Discussion}

Previous studies indicated that chlordane, lindane, and OCPs, including DDT and DDE, possess estrogenic, antiestrogenic, or antiandrogenic effects (Danzo, 1998). These effects might be accomplished by direct binding of these materials to estrogen or androgen receptors, as well as affecting the activities of sex hormone-metabolizing enzymes (Colborn et al., 1993; Crain and Guillette, 1998; Danzo, 1998; Taylor and Harrison, 1999). Chlordane shows complicated and variable biological functions similar to estrogen does in mice (Cranmer et al., 1984; Cassidy, 1994), while lindane inhibits the cholesterol side-chain cleavage activity in mice and may have both estrogenic (Lahiri et al., 1985) and antiestrogenic effects (Chadwick et al., 1988; Cooper et al., 1989). In this study, we observed that hemolymphatic $17 \beta$-estradiol level in female $N$. denticulata can be affected after exposure to chlordane and lindane, (Fig. 1). Although $17 \beta$-estradiol was found to be the main substance responsible for the regulation of female reproductive system

Table 1

Reproduction capability of female Neocaridina denticulata exposed to $17 \beta$-estradiol, chlordane, and lindane

\begin{tabular}{lllllll}
\hline Treatment & $N^{\text {a }}$ & Lag time to oogenesis (days) & Body length $(\mathrm{cm})$ & Eggs produced $^{\mathrm{d}}$ & Eggs hatched $^{\mathrm{d}}$ & Egg diameter $(\mathrm{mm})^{\text {(n) }}$ \\
\hline Control & 8 & $48.8 \pm 7.1$ & $1.84 \pm 0.17$ & $31.4 \pm 8.1$ & $23.0 \pm 8.1$ & $1.04 \pm 0.01$ \\
E2-10 & 8 & $31.8 \pm 6.9^{*}$ & $1.78 \pm 0.04$ & $52.8 \pm 6.0^{*}$ & $13.5 \pm 6.0^{*}$ & $1.12 \pm 0.01^{*}$ \\
E2-100 & $2^{\mathrm{b}}$ & - & - & - & - & - \\
CH-1 & 6 & $36.7 \pm 5.8$ & $1.84 \pm 0.05$ & $27.3 \pm 24.8$ & $1.3 \pm 2.3^{*}$ & $1.09 \pm 0.04$ \\
CH-10 & 0 & - & - & - & - & - \\
L0.1 & 2 & $25.0 \pm 1.4^{*}$ & $1.75 \pm 0.07$ & $14.0 \pm 1.4^{*}$ & 0 & $1.11 \pm 0.01^{*}$ \\
L1 & $1^{\mathrm{c}}$ & - & - & - & - & - \\
\hline
\end{tabular}

An asterisk $(*)$ indicates that a difference between the experimental and control group was significant at $p<0.05$.

E2-10, E2-100: experimental groups of 10 and $100 \mu \mathrm{g}^{-1} 17 \beta$-estradiol.

$\mathrm{CH}-1, \mathrm{CH}-10$ : experimental groups of 1 and $10 \mathrm{ng} \mathrm{1^{-1 }}$ chlordane.

L0.1, L1: experimental groups of 0.1 and $1 \mu \mathrm{g}^{-1}$ lindane.

${ }^{a}$ Twenty female shrimp were used from each treatment group.

b Two shrimp died within 1 and 3 days after oogenesis.

${ }^{c}$ Shrimp died within 1 day after oogenesis.

d Number egg for each shrimp. 
(Hasegawa and Hirose, 1993; Safe et al., 1998), and an increased hemolymphatic $17 \beta$-estradiol was observed in chlordane- or lindane-exposed female $N$. denticulata, these evidences were still insufficient to assure the existence of estrogen-like effects of chlordane and lindane on female $N$. denticulata. Therefore, we further examined the stimulatory effect of estrogen on vitellogenesis in chlordane- or lindaneexposed female $N$. denticula via $\mathrm{Vg}$ assay. This is extremely important for supporting the validity and reliability of the experiment (Colborn et al., 1993; Parks and LeBlanc, 1996; Colborn and Thayer, 2000). When female $N$. denticulata exposed to $17 \beta$-estradiol, chlordane, or lindane, the level of $\mathrm{Vg}$ was significantly higher than that of control animals (Fig. 2). Vg is a precursor of the yolk proteins (Vazquez Boucard et al., 2002). Unlike fish in which Vg synthesis occurs in the liver, Vg is thought to be synthesized in both hepatopancreas and ovaries in crustaceans (Tseng et al., 2002; Tsang et al., 2003). However, other researches show that hepatopancreas is the sole synthesis site of $\mathrm{Vg}$ in freshwater giant prawn, Macrobrachiun rosenbergii, through localization of $\mathrm{Vg}$ expression (Tseng et al., 2001). Beside, 17 $\beta$-estradiol is synthesized in ovaries shrimp (Quinitio et al., 1991). Although we could not rule out the possibility of multiple sites of sources, we speculate that in $N$. denticulata hemolymph $17 \beta$-estradiol and vitellogenin may come from hepatopancrea and ovary, respectively. Results showed that high concentration of chlordane and low both concentration of lindane induced vitellogenin on day1, but not E2 which needs 3 days. There is little data in the literature with regard to the vitellogenesis induced by chlordane, lindane and E2 in shrimp and other animals. It is suggested that lindane at some concentrations could change the permeability of the cell membrane in shrimp, thus enhance the entrance rate of lindane to the cell (López-Aparicio et al., 1994). Anyhow, it is obvious that chlordane and lindane affect not only the level of estrogen in the body of female $N$. denticulate, but also the estrogen-associated vitellogenesis. Thus, we considered that chlordane and lindane possess xenoestrogenic effects in female $N$. denticulate and act as endocrine disruption chemicals (EDCs), which are also supported by our previous findings that in a chlordane- and lindane-treated group on the juvenile and male $N$. denticulata , 17 $\beta$-estradiol secretion and $\mathrm{Vg}$ synthesis were both increased (Huang and Chen, 2004; Huang et al., 2004).

When exogenous EDCs enter the body of animal, they disturb the balance of hormone, retard growth and development, alter the morphological appearance, and even change the sex ratio and decrease the fertility of animal (Colborn et al., 1993). Our study showed that chlordane and lindane reduced the fertility of female $N$. denticulata (Table 1). EDCs have been shown to alter the normal sexual characteristics and fertility of aquatic organisms (Colborn et al., 1993; Taylor and Harrison, 1999). Therefore, the function of reproduction is an important biological indicator for estimating the extent to which a species is affected (Fingerman et al., 1998). Our results showed that female $N$. denticulata was unable to become gravid when exposed to $17 \beta$-estradiol $\left(100 \mu \mathrm{g}^{-1}\right)$, chlordane $\left(10 \mathrm{ng}^{-1}\right)$, or lindane $\left(1 \mu \mathrm{g} \mathrm{l}^{-1}\right)$ (Table 1). The lag time to oogenesis, ovigerous time, ovigerous rate, hatching rate and size of eggs were all altered in female $N$. denticulata when exposed to a low concentration of $17 \beta$-estradiol $\left(10 \mu \mathrm{g}^{-1}\right)$, chlordane $\left(1 \mathrm{ng} \mathrm{l}^{-1}\right)$, or lindane $\left(0.1 \mu \mathrm{g} \mathrm{1^{-1 }}\right)$ (Table 1). According to these results, we believe that the reproductive activity and fertility of $N$. denticulata were affected. Kovacs et al. (1995) demonstrated that the sexual maturation age, the spawning amount, and sex ratio of Pimephales promelas were all affected by bleached kraft mill effluent (BKME). In addition, the brooding time of zebrafish (Danio rerio) eggs was found shortened by ethynyl estradiol, and the spawning amount was also reduced (Kime and Nash, 1999; Kime et al., 1999). Similarly, after exposure to cadmium and tributyltin, spawning amount of Callinectes sapidus was also reduced (Lee, 1998). It is speculated that organisms have to decrease or transfer the energy from reproduction to detoxification or protection mechanisms against the toxicity of xenobiotics, in order to maintain their life (Klaassen, 2001). In order to assure the survival of progeny, organisms might accelerate their reproductive cycles or increase egg numbers when they were exposed to toxicants. Under this circumstance, eggs might become smaller and increase in number (Klaassen, 2001). In this study, we found that it was almost impossible for female $N$. denticulata to become gravid when exposed to $100 \mu \mathrm{g} 1^{-1} 17 \beta$-estradiol, $10 \mathrm{ng}^{-1}$ chlordane, or $1 \mu \mathrm{g}^{-1}$ lindane. Some treated female shrimps even died during their gravid time. It is clear that gravid female $N$. denticulata were sensitive to $100 \mathrm{gg}^{-1} 17 \beta$-estradiol, $10 \mathrm{ng}^{-1}$ chlordane, and $1 \mu \mathrm{g}^{-1}$ lindane. Based on out results, we speculated that female $N$. denticulata decrease or transfer energy normally used for reproduction to the use for maintain life when exposed to $100 \mu \mathrm{g}^{-1} 17 \beta$-estradiol, $10 \mathrm{ng} \mathrm{l}^{-1}$ chlordane, or $1 \mu \mathrm{g} 1^{-1}$ lindane. Chen et al. (2000) reported that $17 \beta$-estradiol could accelerate the sexual maturation and increase spawning amount of female shrimp, and might be able to be applied in aquaculture. However, there are still some different points of view existing concerning the application of vertebrate hormones in cultivation of invertebrates (Okumura, 2004).

We demonstrated that exposure to 17ß-estradiol $\left(10 \mu \mathrm{g}^{-1}\right)$ accelerated the maturation time and spawning amount of female $N$. denticulate, but decreased the hatching rate of eggs. It is likely that the continuously exposure to the toxicity of $17 \beta$-estradiol caused the decreased in hatching rate The decrease in hatching rate might be recovered if the exposure dose of $17 \beta$-estradiol was reduced or if moving the ovigerous females to a clean, un-contaminated freshwater. Furthermore, increase of $17 \beta$-estradiol and $\mathrm{Vg}$ levels in female $N$. denticulate exposed to chlordane and lindane revealed that these two pesticides functioned as estrogen-like materials in $N$. denticulata. Even so, we found that ovigerous amounts of female $N$. denticulata exposed to chlordane and lindane were not as high as those exposed to $17 \beta$-estradiol. We hypothesized that the toxicities of chlordane and lindane directly damaged the gonads and in turn 
decreased the reproductive activity. Further research is under conduction to verify the hypothesis with the focus on histological evidence of the damages in gonads of $N$. denticulate caused by chlordane and lindane.

\section{References}

Cardoso, A.M., Barros, C.M.F., Correia, A.J.F., 1997. Identification of vertebrate type steroid hormones in the shrimp Penaeus japonicus by tandem mass spectrometry and sequential product ion scanning. J. Am. Soc. Mass Spectrom. 8, 365-370.

Cassidy, R.A., 1994. The effects of chlordane exposure during pre- and post-natal periods at environmentally relevant levels on sex steroidmediated behaviors and functions in the rat. Toxicol. Appl. Pharmacol. 126, 326-337.

Chadwick, R.W., Cooper, R.L., Chang, J., Rehnberg, G.L., McElory, W.K., 1988. Possible antiestrogenic activity of lindane in female rats. J. Biochem. Toxicol. 3, 147-158.

Chen, H.C., Wang, Y.S., Yuan, J.H., 1999. Standard methods to study and detect bioaccumulation in fish and shellfish (EPA-88-1502-03-01). Environmental Protection Administration of Taiwan, Taipei, Taiwan (in Chinese).

Chen, S.-N., Sheen, S.-S., Nan, F.-H., Lin, C.-L., Wang, C.S., Lye, K.C., 2000. Technology in Shrimp Culture. Aquarium World Mag, Taiwan (in Chinese).

Colborn, T., Vom-Saal, F.S., Soto, A.M., 1993. Developmental effects of endocrine disrupting chemicals in wildlife and humans. Environ. Health Perspect. 101, 378-384.

Colborn, T., Thayer, K., 2000. Aquatic ecosystems: harbingers of endocrine disruption. Ecol. Appl. 10, 949-957.

Cooper, R.L., Chadwick, R.W., Rehnberg, G.L., Goldman, J.M., Booth, K.C., Hein, J.F., McElroy, W.K., 1989. Effect of lindane on hormonal control of reproductive function in the female rat. Toxicol. Appl. Pharmacol. 99, 384-394.

Crain, D.A., Guillette Jr., L.J., 1998. Reptiles as models of contaminantinduced endocrine disruption. Anim. Reprod. Sci. 53, 77-86.

Cranmer, J.M., Cranmer, M.F., Goad, P.T., 1984. Prenatal chlordane exposure: effects on plasma corticosterone concentrations over the lifespan of mice. Environ. Res. 35, 204-210.

Danzo, B.J., 1998. The effects of environmental hormones on reproduction. Cell. Mol. Life Sci. 54, 1249-1264.

Depledge, M.H., Billinghurst, Z., 1999. Ecological significance of endocrine disruption in marine invertebrates. Mar. Pollut. Bull. 39, 3238.

Englund, R.A., Cai, Y., 1999. The occurrence and description of Neocaridina denticulate sinensis (Kemp, 1918) (Crustacea: Decapoda: Atyidae), a new introduction to Hawaiian Island. Bishop Mus. Occas. Papers 58, 58-65.

Ellman, G.L., Courtney, K.D., Andres, V., Featherstone, R.M., 1961. A new and rapid colorimetric determination of acetylcholinesterase activity. Biochem. Pharmacol. 7, 88-95.

EPA/ROC. 1998. Standard guide for conducting acute tests with shrimps: static renewal test for Neocaridina denticulata (NIEA B905.10B), Taiwan, Taipei: Environmental Protection Administration of Taiwan (in Chinese).

Fingerman, M., Jackson, N.C., Nagabhushanam, R., 1998. Hormonallyregulated functions in crustaceans as biomarkers of environmental pollution. Comp. Biochem. Physiol. C Pharmacol. Toxicol. Endocrinol. 120, 343-350.

Gangé, F., Blaise, C., 2000. Organic alkali-labile phosphates in biological materials: a generic assay to detect vitellogenin in biological tissues. Environ. Toxicol. 15, 243-247.

Hasegawa, Y., Hirose, E., 1993. Hormonal control of sexual differentiation and reproductive in crustacean. Am. Zool. 33, 403-411.

Huang, D.-J., Chen, H.-C., 2004. Effects of chlordane and lindane on testosterone and vitellogenin levels in green neon shrimp (Neocaridina denticulata). Int. J. Toxicol. 232, 91-96.
Huang, D.-J., Wang, S.-Y., Chen, H.-C., 2004. Effects of the endocrine disrupter chemicals chlordane and lindane on the male green neon shrimp (Neocaridina denticulata). Chemosphere 57, 1621-1627.

Hung, M.S., Chan, T.Y., Yu, H.P., 1993. Atyid shrimps (Decapoda: Caridea) of Taiwan, with descriptions of three new species. J. Crustac. Biol. 13, 481-503.

Hutchinson, T.H., 2002. Reproductive and developmental effects of endocrine disrupters in invertebrates: in vitro and in vivo approaches. Toxicol. Lett. 131, 75-81.

Kime, D.E., Nash, J.P., 1999. Gamete viability as indicator of reproductive endocrine disruption in fish. Sci. Total Environ. 233, 123-129.

Kime, D.E., Nash, J.P., Scott, A.P., 1999. Vitellogenesis as a biomarker of reproductive disruption by xenobiotics. Aquaculture 177, 345-352.

Klaassen, C.D., 2001. Casarett and Doull's Toxicology. McGraw-Hill, New York.

Kovacs, T.G., Gibbons, J.S., Tremblay, L.A., O’Connor, B.I., Martel, P.H., Voss, R.I., 1995. The effects of a secondary-treated bleached Kraft mill effluent on aquatic organisms as assessed by short-term and long-term laboratory tests. Ecotoxicol. Environ. Safety 31, 7-22.

Lahiri, P., Chakravarty, S., Mondal, A., Sircar, S., 1985. Effect of lindane on cytology and cyto-chemistry of exfoliated vaginal cells. Exp. Clin. Endocrinol. 85, 303-308.

Lee, P.C., 1998. Disruption of male reproductive tract development by administration of the xenoestrogen, nonylphenol, to male newborn rats. Endocr. J. 9, 105-111.

López-Aparicio, P., Recio, M.N., Prieto, J.C., Pérez-Albarsanz, M.A., 1994. Role of lindane in membranes. Effect on membrane fluidity and activity of membrane-bond protein. Biosci. rep. 14, 131-138.

Maxey, K.M., Maddipati, K.R., Birkmeter, J., 1992. Interference in enzyme immunoassays. J. Clin. Immunoassay 15, 120-166.

Okumura, T., 2004. Perspectives on hormonal manipulation of shrimp reproduction. Jpn. Agric. Res. Q. 38, 49-54.

Parks, L.G., LeBlanc, G.A., 1996. Reductions in steroid hormone biotransformation/elimination as a biomarker of pentachlorophenol chronic toxicity. Aquat. Toxicol. 34, 291-303.

Quinitio, E.T., Yamauchi, K., Hara, A., Fuji, A., 1991. Profiles of progesterone- and estradiol-like substances in the hemolymph of female Pandalus kessleri during an annual reproductive cycle. Gen. Comp. Endocrinol. 81, 343-348.

Rinderhagen, M., Ritterhoff, J., Zauke, G.P., 2000. Crustaceans as bioindicators. Environ. Res. 9, 161-194.

Safe, S., Connor, K., Gaido, K., 1998. Methods for xenoestrogen testing. Toxicol. Lett. 102-103, 665-670.

Sharara, F.I., Seifer, D.B., Flaws, J.A., 1998. Environmental toxicants and female reproduction. Fertil. Steril. 70, 613-622.

Shy, J.Y., Yu, H.P., 1998. Freshwater shrimps of Taiwan. National Museum of Marine Biology and Aquarium, Taipei, Taiwan (in Chinese).

Taylor, M.R., Harrison, P.T.C., 1999. Ecological effects of endocrine disruption: current evidence and research priorities. Chemosphere 39, 1237-1248.

Tsang, W.S., Quackenbush, L.S., Chow, B.K.C., Tiu, S.H.K., He, J.G., Chan, S.M., 2003. Organization of the shrimp vitellogenin gene: evidence of multiple genes and tissue specific expression by the ovary and hepatopancreas. Gene 303, 99-109.

Tseng, D.Y., Chen, Y.N., Kou, G.H., Lo, C.F., Kuo, C.M., 2001. Hepatopancreas is the extraovarian site of vitellogenin synthesis in black tiger shrimp, Penaeus monodon. Comp. Biochem. Physiol. A 129, 909-917.

Tseng, D.Y., Chen, Y.N., Liu, K.F., Kou, G.H., Lo, C.F., Kuo, C.M., 2002. Hepatopancreas and ovary are sites of vitellogenin synthesis as determined from partial cDNA encoding of vitellogenin in the marine shrimp, Penaeus vannamei. Invertebr. Reprod. Dev. 42, 137-143.

Vazquez Boucard, C.G., Levy, P., Ceccaldi, H.J., Brogen, C.H., 2002. Developmental changes in concentrations of vitellin, vitellogenin, and lipids in hemolymph, hepatopancreas and ovaries from different ovarian stages of Indian white prawn Fenneropenaeus indicus. J. Exp. Mar. Biol. Ecol. 281, 63-75. 